\title{
Roles of differential expression of microRNA-21-3p and microRNA-433 in FSH regulation in rat anterior pituitary cells
}

\author{
Dong-Xu Han ${ }^{1}$, Xu-Lei Sun ${ }^{1}$, Ming-Qiang $X_{u^{1}}{ }$, Cheng-Zhen Chen ${ }^{1}$, Hao Jiang ${ }^{1}$, \\ Yan Gao', Bao Yuan' ${ }^{1}$ and Jia-Bao Zhang ${ }^{1}$ \\ ${ }^{1}$ Department of Laboratory Animals, College of Animal Sciences, Jilin University, Changchun, Jilin, P.R. China \\ Correspondence to: Jia-Bao Zhang, email: zjb515@126.com \\ Bao Yuan, email: yuanbao1982@163.com \\ Keywords: rat anterior pituitary cell, FSH secretion, miR-21-3p, miR-433, animal reproduction \\ Received: February 06, $2017 \quad$ Accepted: March 11, $2017 \quad$ Published: March 28, 2017 \\ Copyright: Han et al. This is an open-access article distributed under the terms of the Creative Commons Attribution License (CC-BY), \\ which permits unrestricted use, distribution, and reproduction in any medium, provided the original author and source are credited.
}

\section{ABSTRACT}

Follicle-stimulating hormone (FSH) secreted by adenohypophyseal cells plays an important role in the regulation of reproduction, but whether microRNAs (miRNAs) regulate the secretion of FSH remains unclear. In the present study, we predicted and screened miRNAs that might act on the follicle-stimulating hormone beta-subunit (FSHb) gene of rats using the TargetScan program and luciferase reporter assays, and the results identified two miRNAs, miR-21-3p and miR-433. We then transfected these miRNAs into rat anterior adenohypophyseal cells and assessed the FSHb expression levels in and FSH secretion by the transfected cells through quantitative PCR and ELISA. The results showed that both miR-21-3p and miR-433 down-regulated the expression levels of FSHb and resulted in the decrease of the secretion of FSH compared with the control group, and treatment with miR-21-3p and miR-433 inhibitors up-regulated the expression levels of FSHb and resulted in the increase of the secretion of FSH. Taken together, our results indicate that miR-21-3p and miR-433 can down-regulate the expression of FSHb by directly targeting the FSHb $3^{\prime}$ UTR in rat primary pituitary cells. Our findings provide evidence that miRNAs can regulate FSHb expression and further affect the secretion of FSH and might contribute to the use of miRNAs for the regulation of animal reproduction.

\section{INTRODUCTION}

The pituitary, which is the most important endocrine organ in animals, functions as a main regulator of numerous physiological processes through its control of downstream endocrine glands [1]. Seven types of hormones secreted from the pituitary play important roles in the regulation of organismal activities [2]. Follicle-stimulating hormone (FSH), one of the gonadotropin hormones (GTH), is a pivotal regulator of reproduction [3]. FSH regulates the production of several growth factors that play a vital role in early folliculogenesis and animal reproduction [4-6].

FSH, a glycoprotein hormone encoded by the FSHb gene [7], comprises two subunits, specifically a common $\alpha$ subunit and a unique $\beta$ subunit, which are involved in specific biological activities [3, 7]. In males, FSH regulates spermatogenesis, and in females, this hormone is indispensable for oogenesis [3]. FSH binds to the follicle stimulating hormone receptor (FSHR) located on Sertoli cells of the testis and granulosa cells of the ovaries to transmit its signal and exert its functions [8]. Numerous studies have indicated that FSH secretion is regulated by many factors. Lower expression levels of gonadotropin releasing hormone receptor (GnRHR) can stimulate maximal production of FSH [9], and at the transcriptional level, FSH secretion is mainly regulated by the gonadotropin releasing hormone $(\mathrm{GnRH})$ signaling pathway [10]. Furthermore, the genetic linkage of novel single-nucleotide polymorphisms (SNPs) within bovine FSHb can influence the serum FSH concentrations [11].

The miRNAs are a family of short, non-coding RNAs that can play crucial roles in both animals and plants $[12,13]$. miRNAs can combine with the mRNAs of protein-coding genes to decrease the translational efficiency or modulate the post-transcriptional levels of the mRNAs [14]. Numerous miRNAs have been identified 
in nearly all metazoan genomes examined since the discovery of the two first miRNAs, lin-4 and let-7 [12, $15,16]$, and many studies have reported that miRNAs can influence hormone regulation. For example, miR-26b upregulates the growth hormone levels by targeting lymphoid enhancer binding factor 1 (Lef-1) in GH3 cells, whereas miR-129-5p, miR-202 and two other miRNAs repress the human growth hormone receptor (GHR) expression levels in both normal and cancer cells $[17,18]$. However, it remains unclear whether $\mathrm{FSH}$ secretion is regulated by miRNAs.

In this study, we used the TargetScan program, a luciferase reporter assay and quantitative RT-PCR to identify the miRNAs that target the 3'UTR of the FSHb mRNA. In addition, the sequence of the 3'UTR of FSHb mRNA was mutated to validate the interaction between the identified miRNAs and the FSHb mRNA. To investigate whether the identified miRNAs can affect FSH secretion, we transfected the candidate miRNAs into primary rat pituitary cells and measured the $\mathrm{FSHb}$ gene expression levels in and the secretion of the FSH hormone from the transfected cells.

\section{RESULTS}

\section{Identification of miRNAs that potentially target the FSHb 3'UTR}

To identify rat miRNAs that potentially target the 3'UTR of the FSHb gene, we used the TargetScan program to predict 150 miRNAs that could target the 3'UTR of the FSHb mRNA at the post-transcriptional level (Supplementary Table 1). After deleting the duplicate target sites and miRNAs that are not expressed in the rat pituitary based on to the results of a previous microarray study [2], we selected 45 preferred candidate miRNAs (Table 1). To comprehensively verify the interactions between these miRNAs and the FSHb mRNA, we constructed a reporter plasmid, pmiR-FSHb-3'UTR-WT (Supplementary File 2), in which the FSHb 3'UTR was cloned downstream of a firefly luciferase reporter gene. We then used a screening system based on the luciferase reporter plasmid carrying the full-length 3'UTR of the FSHb mRNA and found that 18 miRNAs, specifically miR-433-3p, miR-323-3p, miR-328a-3p, miR-3573-3p, miR-204-5p, miR-206-5p, miR-31a-5p, miR-7a-5p, miR880-3p, miR-186-5p, miR-503-5p, miR-383-5p, miR-3245p, miR-505-5p, miR-27b-3p, miR-221-5p, miR-320-3p and $\operatorname{miR}-21-3 p$, could suppress the expression of the reporter by more than $30 \%$ (Figure 1 ).

\section{Detection of the expression of the identified miRNAs at different developmental stages}

To determine whether the expression levels of the identified miRNAs varied at different developmental stages, we measured the expression levels of miRNAs that were randomly selected from the set of identified miRNAs at different developmental stages in the rat pituitary. Rats were grouped according to their ages into one of two groups, specifically the 15-day-old and 4-monthold groups, to represent two different developmental stages. To ensure the accuracy of the experiment, we first measured the expression levels of $\mathrm{FSHb}$ in the pituitary at the two developmental stages. The results indicated that the level of FSHb was increased (3.12-fold) in the sexual maturity period compared with that detected in the non-sexual maturity period (Figure 2A). Moreover, the results showed that 13 miRNAs were down-regulated in the sexual maturity period compared with their levels in the non-sexual maturity period, whereas one miRNA was up-regulated (Figure 2B). We then randomly selected two miRNAs from the set of 13 down-regulated miRNAs (miR-21-3p and miR-433) for subsequent analysis, and the results suggested that miR-21-3p and miR-433 downregulated $\mathrm{FSHb}$ in the sexual maturity stage compared with the non-sexual maturity stage (Figures 2C and 2D).

\section{Validation of the interaction between the miRNAs and FSHb in vitro}

To examine whether the silencing of $\mathrm{FSHb}$ is mediated by the specific, direct interaction of miR-21-3p and miR-433 with the FSHb target site, we predicted the respective target positions of the two miRNAs in the FSHb 3'UTR using the TargetScan program (Figures 3A and $3 \mathrm{~B})$, and we then mutated the complementary sites of the two miRNA seed regions to generate pmiR-FSHb-3'UTRMUT and pmiR-FSHb-3'UTR-MUT1 (Supplementary File 3 ). We then cotransfected miR-21-3p mimics and pmiRFSHb-3'UTR-WT into $293 \mathrm{~T}$ cells, which led to a $\sim 60 \%$ reduction in luciferase activity; interestingly, cotransfection of the miR-21-3p mimics and pmiR-FSHb-3'UTR-MUT into $293 \mathrm{~T}$ cells yielded no significant changes in luciferase activity (Figure 3C). Similarly, co-transfection of miR433 and pmiR-FSHb-3'UTR-WT into 293T cells yielded a more than a $30 \%$ decrease in luciferase activity, whereas cotransfection of miR-433 and pmiR-FSHb-3'UTR-MUT1 yielded no changes in luciferase activity (Figure 3D). Therefore, the results suggested that miR-21-3p and miR433 can regulate the expression of $\mathrm{FSHb}$.

\section{Effect of miR-21-3p and miR-433 transfection on rat primary pituitary cells}

To detect the growth of cultured primary pituitary cells after transfection with miR-21-3p and miR-433, we observed the growth of the pituitary cells and noted that they appeared to be in good condition (Figures 4A-4D). To determine the transfection efficiency achieved with a $100 \mathrm{nM}$ concentration of the negative controls, mimics, inhibitor negative controls and inhibitors of miR-21-3p 
Table 1: The final 45 miRNAs

\begin{tabular}{|c|c|c|c|}
\hline miRNA & Position in the UTR & seed match & context++ score \\
\hline rno-let-7f-2-3p & $926-933$ & 8 mer & -0.32 \\
\hline rno-miR-103-3p & $761-767$ & 7 mer-m8 & -0.27 \\
\hline rno-miR-10a-5p & $598-604$ & 7 mer-m8 & none \\
\hline rno-miR-124-3p & $95-101$ & $7 \mathrm{mer}-1 \mathrm{~A}$ & -0.01 \\
\hline rno-miR-144-5p & $47-53$ & 7 mer-m8 & -0.02 \\
\hline rno-miR-148b-3p & $74-80$ & 7 mer-m8 & -0.16 \\
\hline rno-miR-16-5p & $762-769$ & 8 mer & -0.41 \\
\hline rno-miR-185-5p & $835-841$ & $7 \mathrm{mer}-\mathrm{m} 8$ & -0.18 \\
\hline rno-miR-186-5p & $677-683$ & $7 \mathrm{mer}-1 \mathrm{~A}$ & -0.01 \\
\hline rno-miR-199a-3p & $1152-1158$ & 7 mer-1A & -0.01 \\
\hline rno-miR-19b-2-5p & $777-783$ & 7 mer-m8 & -0.16 \\
\hline rno-miR-204-5p & $326-332$ & 7 mer-m8 & -0.09 \\
\hline rno-miR-206-5p & $434-440$ & 7 mer-1A & -0.11 \\
\hline rno-miR-206-5p & $579-585$ & 7 mer-m8 & -0.13 \\
\hline rno-miR-21-3p & $970-976$ & 7mer-m8 & -0.11 \\
\hline rno-miR-214-5p & $241-247$ & 7 mer-1A & -0.17 \\
\hline rno-miR-223-3p & $132-138$ & 7 mer-1A & -0.13 \\
\hline rno-miR-27b-3p & $714-721$ & 8 mer & -0.41 \\
\hline rno-miR-296-3p & $308-314$ & 7 mer-m8 & -0.2 \\
\hline rno-miR-298-5p & $71-77$ & $7 \mathrm{mer}-1 \mathrm{~A}$ & -0.04 \\
\hline rno-miR-299b-5p & $86-93$ & $8 \mathrm{mer}$ & -0.27 \\
\hline rno-miR-30c-1-3p & $837-843$ & 7 mer-m8 & -0.18 \\
\hline rno-miR-31a-5p & $516-523$ & 8 mer & -0.29 \\
\hline rno-miR-320-3p & $829-835$ & 7 mer-m8 & -0.12 \\
\hline rno-miR-323-3p & $1368-1374$ & 7 mer-m8 & none \\
\hline rno-miR-324-3p & $845-851$ & 7 mer-1A & -0.07 \\
\hline rno-miR-324-5p & $329-336$ & $8 \mathrm{mer}$ & -0.55 \\
\hline rno-miR-328a-3p & $172-178$ & 7 mer-m8 & -0.13 \\
\hline rno-miR-339-5p & $597-603$ & 7mer-m8 & -0.35 \\
\hline rno-miR-340-5p & $1219-1225$ & $7 \mathrm{mer}-1 \mathrm{~A}$ & none \\
\hline rno-miR-343 & $345-351$ & 7 mer-m8 & -0.25 \\
\hline rno-miR-344b-1-3p & $1181-1187$ & 7 mer-1A & -0.13 \\
\hline rno-miR-34b-5p & $92-98$ & 7mer-m8 & -0.29 \\
\hline rno-miR-3573-3p & $291-297$ & 7 mer-1A & -0.03 \\
\hline rno-miR-3596d & $927-933$ & $7 \mathrm{mer}-1 \mathrm{~A}$ & none \\
\hline
\end{tabular}

(Continued) 


\begin{tabular}{lccc}
\hline miRNA & Position in the UTR & seed match & context++ score \\
\hline rno-miR-378a-3p & $339-346$ & $8 \mathrm{mer}$ & -0.35 \\
rno-miR-383-5p & $820-826$ & 7 mer-1A & -0.11 \\
rno-miR-409a-5p & $639-645$ & 7 mer-1A & -0.19 \\
rno-miR-433-3p & $1044-1050$ & 7 mer-m8 & -0.14 \\
rno-miR-449c-3p & $674-680$ & 7 mer-m8 & -0.13 \\
rno-miR-503-5p & $763-769$ & 7 mer-1A & -0.22 \\
rno-miR-505-5p & $111-117$ & 7 mer-1A & -0.14 \\
rno-miR-7a-5p & $572-578$ & 7 mer-1A & -0.01 \\
rno-miR-880-3p & $586-592$ & 7 mer-1A & -0.11 \\
rno-miR-9a-3p & $272-278$ & 7 mer-1A & -0.1 \\
\hline
\end{tabular}

and miR-433, we measured the expression levels of the two miRNAs, and the results showed that transfection of the miR-21-3p mimic significantly increased the expression level of miR-21-3p, whereas transfection of the miR-21-3p inhibitor significantly decreased the expression level of miR-21-3p (Figure 4E). We observed a similar pattern for miR-433: the expression level was significantly increased in the mimic group and significantly decreased in the inhibitor group (Figure 4F). These results indicated that the transfection was successful.

\section{miR-21-3p- and miR-433-mediated regulation of the FSHb expression levels in and FSH secretion by rat primary pituitary cells}

To verify that both miR-21-3p and miR-433 target the FSHb gene and to gain further insights into their regulation of reproduction, we measured the expression levels of FSHb in rat primary anterior pituitary cells by quantitative RT-PCR and the secretion of FSH by these cells through ELISA.

We transfected rat primary anterior pituitary cells with the miR-21-3p negative control, mimic, inhibitor negative control or inhibitor at a concentration of $100 \mathrm{nM}$ and subsequently incubated the cells for $24 \mathrm{~h}$. We then measured the expression levels of FSHb in these four groups. Transfection with the miR-21-3p mimic resulted in a 0.70 -fold decrease $(\mathrm{P}<0.05)$ in the expression level of $\mathrm{FSHb}$, whereas transfection with the inhibitor resulted in a 1.40 -fold increase $(\mathrm{P}<0.05)$ in the expression level of $\mathrm{FSHb}$ (Figure 5A). Moreover, a 0.74-fold decrease $(\mathrm{P}<0.05)$ in the FSHb expression level was observed after transfection with the miR-433 mimic, and a 1.37-fold increase $(\mathrm{P}<0.05)$ was detected after transfection with the miR-433 inhibitor (Figure 5B). We then measured FSH secretion at the protein level. Interestingly, the results regarding the $\mathrm{FSHb}$ expression levels and FSH secretion were similar among the four treatment groups. The FSH concentration was deceased significantly [(6.43 \pm 0.28$) \mathrm{IU} / \mathrm{L}$ vs. (4.95 \pm 0.24$) \mathrm{IU} / \mathrm{L}, \mathrm{P}<0.05]$ in the miR-21-3p mimic group compared with the control group and was increased significantly $[(6.67 \pm 0.32) \mathrm{IU} / \mathrm{L}$ vs. $(9.35 \pm 0.48) \mathrm{IU} / \mathrm{L}$, $\mathrm{P}<0.05]$ in the miR-21-3p inhibitor group (Figure 5C). In addition, FSH secretion was decreased [(5.96 \pm 0.33$) \mathrm{IU} / \mathrm{L}$ vs. (3.69 \pm 0.52$) I U / L, P<0.05]$ after transfection with the miR-433 mimic and increased after transfection with the miR-433 inhibitor $[(5.67 \pm 0.35) \mathrm{IU} / \mathrm{L}$ vs. $(8.67 \pm 0.61) \mathrm{IU} / \mathrm{L}$, $\mathrm{P}<0.05]$.

These results demonstrated that both miR-21-3p and miR-433 can regulate FSHb expression by directly binding to the FSHb 3'UTR and inhibiting the FSHb expression levels through the degradation of mRNA and inhibition of translation.

\section{DISCUSSION}

miRNAs are post-transcriptional regulators that play significant roles in cancer, disease, growth and development, and stem cell differentiation [19-21]. In addition, miRNAs are expressed in a tissue-specific, time-dependent manner and control the differentiation or maintenance of tissue identity [22]. Furthermore, miRNAs exert effects on the pituitary, including both pituitary adenomas and the normal pituitary. In pituitary adenomas, the miRNA profiles might provide potential markers for predicting the pituitary adenoma histotypes [23]. Previous studies have shown that miRNAs are important emerging elements in many types of adenomas, such as GH-secreting, PRL-secreting, and non-functional pituitary adenomas [24-26]. In addition, miRNAs can affect the development of the normal pituitary. For example, in 2010, Zichao Zhang et al. reported that miR-26b regulates two main factors, Lef1 and pituitary-specific positive transcription factor 


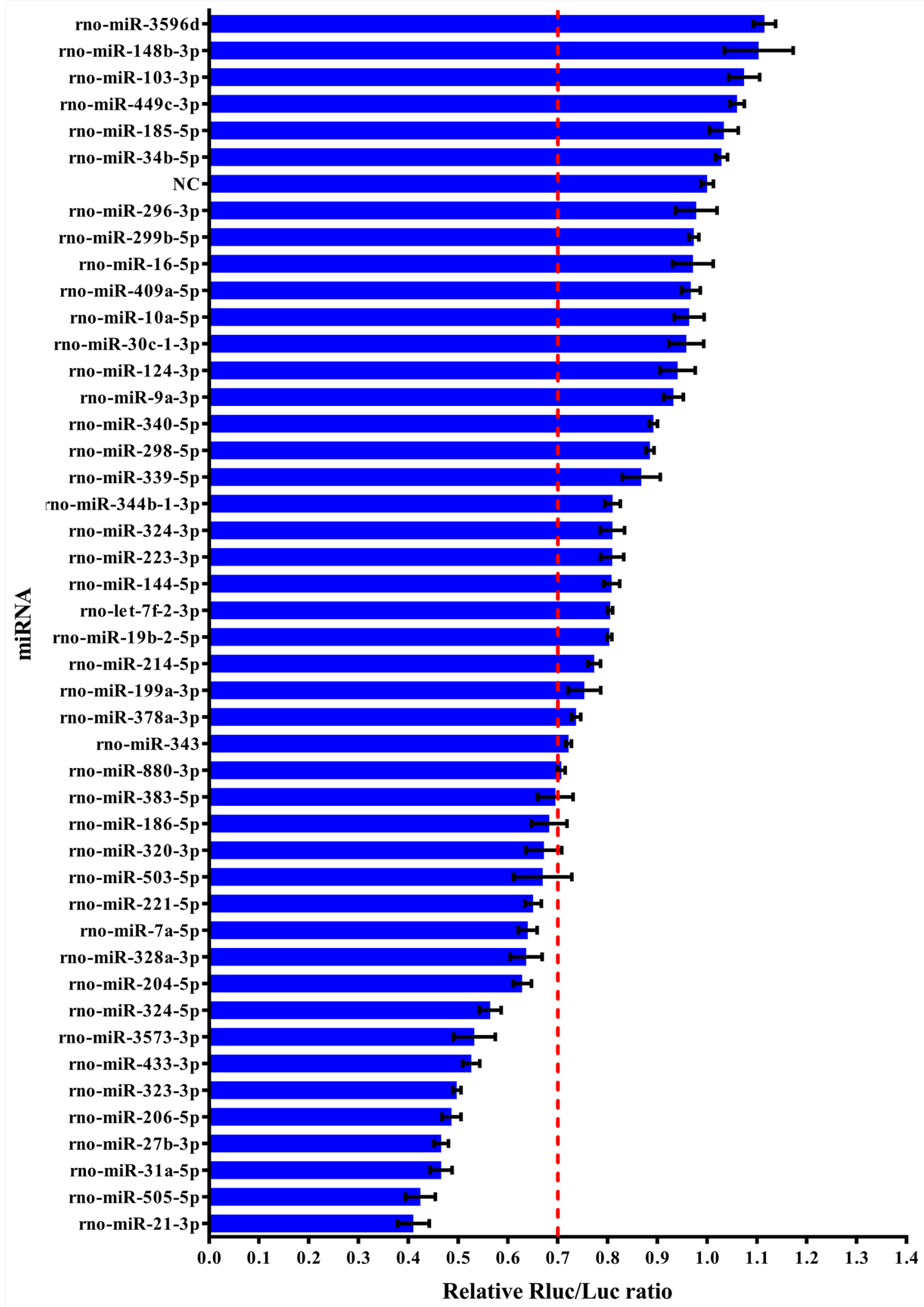

Figure 1: Identification of miRNAs that may target the FSHb 3'UTR. Effects of the predicted 45 miRNAs on the reporter gene expression of the pmiR-FSHb-3'UTR-WT vector. Relative luciferase activity was measured $48 \mathrm{~h}$ after transfection and normalized to the Renilla luciferase activity generated by the co-transfected pmiR-RB-REPORT ${ }^{\mathrm{TM}}$ vector. The normalized relative Rluc/Luc activity ratio for the negative control was set to 1 . 
1(Pit-1), during pituitary development [17]. In 2012, Schneeberger et al. reported that changes in miRNA processing structures can lead to pituitary dysfunction and neurodegeneration, which reveals that miRNAs are important in the physiological functions of the pituitary [27]. miRNAs have also been associated with the secretion of hormones in the pituitary, such as adrenocorticotropic hormone (ATCH) and luteinizing hormone $(\mathrm{LH})[28,29]$. Because miRNAs are required for the physiological functions and development of the normal pituitary, changes in miRNA expression might cause pituitary disorders. In a previous study, we detected 93 differentially expressed miRNAs and found that seven of these miRNAs were significantly differentially expressed at various developmental stages [2]. Building on these previous results, in the present study, we identified miRNAs that are differentially expressed during the sexual maturity developmental stage compared with the non-sexual maturity stage in the rat pituitary through a microarray analysis, use of the TargetScan program, and a luciferase reporter assay. These differentially expressed mRNAs, which include one up-regulated miRNA and 13 down-regulated miRNAs, represent potential regulators of pituitary development and reproduction and highlight new mechanisms involved in these processes. miR-21-3p and miR-433 were selected for the subsequent experiment.

miR-21 belongs to a microRNA family that is highly expressed in many types of mammalian cells [30]. In previous studies, the expression of miR-21 was associated with human colorectal, breast, and lung cancers as well as human glioblastoma cell lines [31-

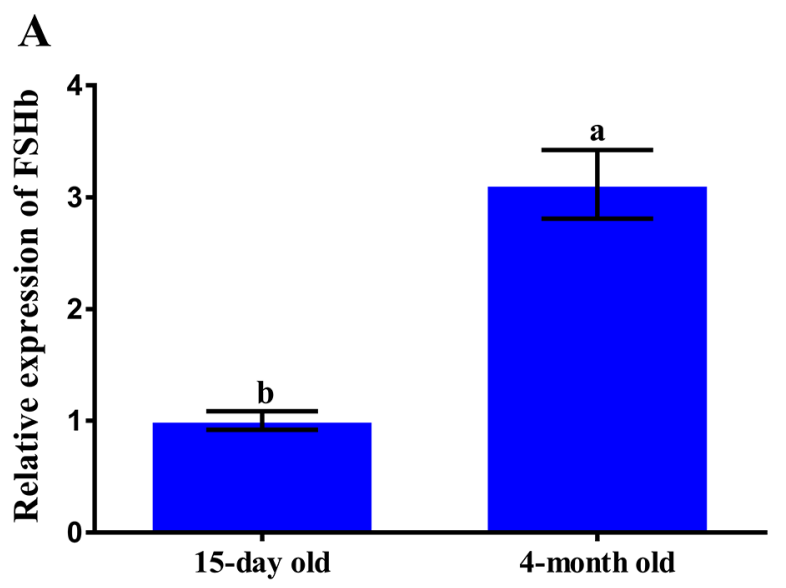

B

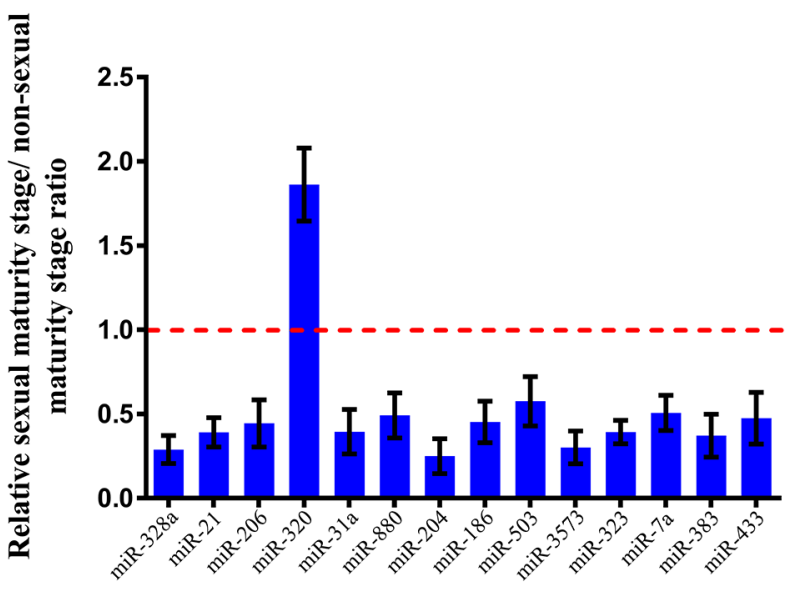

D

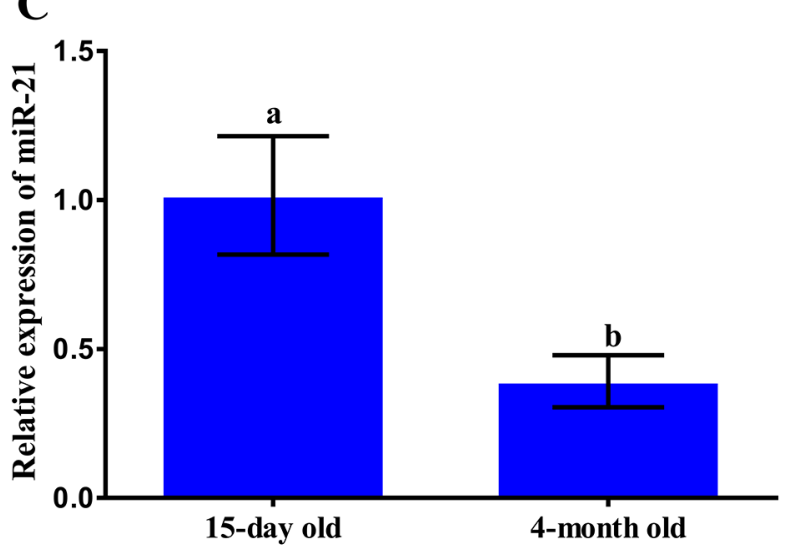

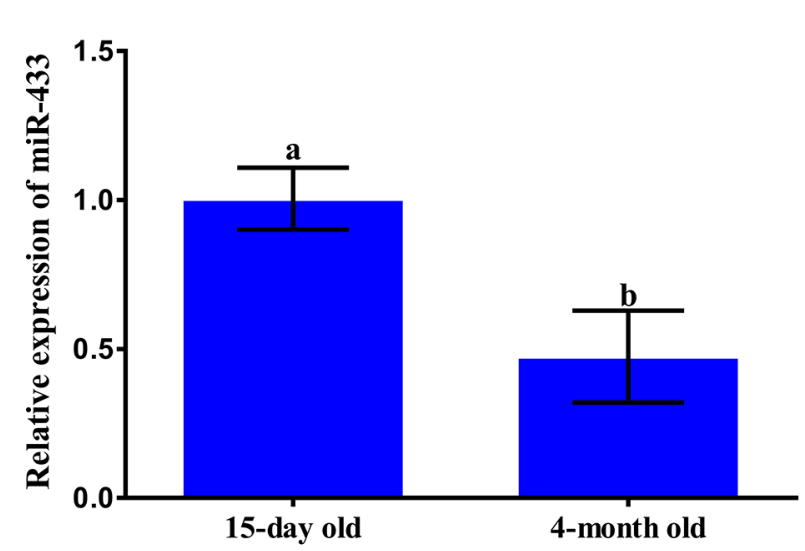

Figure 2: Detection of the expression of the identified miRNAs at different developmental stages. (A) The expression levels of FSHb were determined via quantitative RT-PCR with GAPDH as an internal standard in the pituitary cells of 15-day-old and 4-month-old rats. (B) The expression levels of some of the identified miRNAs were determined through quantitative RT-PCR with U6 as an internal standard at the different developmental stages of the rat pituitary. (C-D) In rat anterior pituitary cells from different developmental stages, derived from 15-day-old and 4-month-old rats, the expression levels of miR-21-3p and miR-433 were separately determined via quantitative RT-PCR with U6 as an internal standard. The data are presented as the mean \pm standard deviation from at least three independent experiments; statistical significance was determined using multiple comparisons; and $\mathrm{P}<0.05$ was considered significant. The panels with different letters were considered statistically significant $(\mathrm{P}<0.05)$. 
A

rno-miR-21-3p: 3'-CUGUCGGGUAGCUGACGACAAC-5'

FSHb 3'UTR: 5'-ACCGUGAGGGAAAACUGCUGUUU-3' (position 970-976)

C

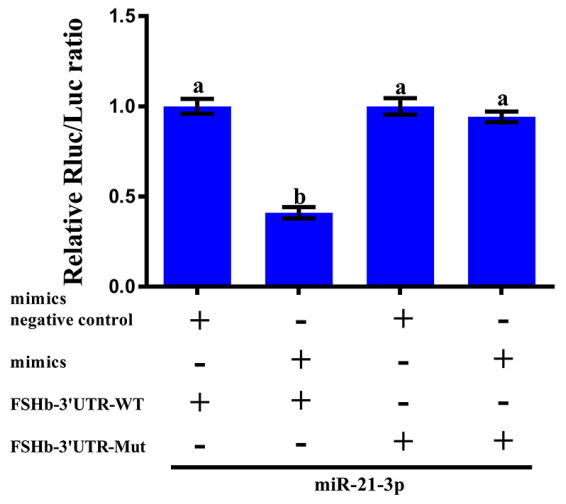

B

rno-miR-433-3p: 3'-GUUCCUUUCAAAUACAUCAUGAG-5 ||||||

FSHB 3'UTR: 5'-UGUGGCUCCUCGGGUAGUACUA-3' (position 1044-1050)
D

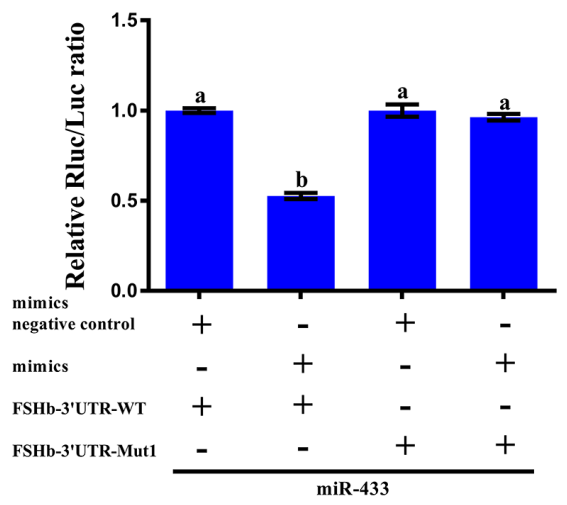

Figure 3: In vitro validation of the interaction between the miRNAs and FSHb. (A) Sequence alignment of miR-21-3p with the 3'UTR of FSHb from the rat. (B) Sequence alignment of miR-433 with the 3'UTR of FSHb in the rat. The seed match region predicted by the TargetScan program is indicated in red. (C) Relative luciferase activity of the pmiR-FSHb-3'UTR-WT (FSHb-3'UTR-WT) and pmiR-FSHb-3'UTR-MUT (FSHb-3'UTR-MUT) vectors in 293T cells cotransfected with the mimic negative controls and miR-21-3p mimics. (D) Relative luciferase activity of the pmiR-FSHb-3'UTR-WT (FSHb-3'UTR-WT) and pmiR-FSHb-3'UTR-MUT1 (FSHb3'UTR-MUT1) vectors in 293 T cells cotransfected with the mimic negative controls and miR-433 mimics. Relative luciferase activity was measured $48 \mathrm{~h}$ after transfection and normalized to the Renilla luciferase activity generated through cotransfection with the pmiR-RBREPORT $^{\mathrm{TM}}$ vector. The normalized luciferase activity for the controls was set to 1 . The data are presented as the mean \pm standard deviation from at least three independent experiments; statistical significance was determined through one-way ANOVA; and $\mathrm{P}<0.05$ was considered significant. The panels with different letters were considered statistically significant $(\mathrm{P}<0.05)$.

A

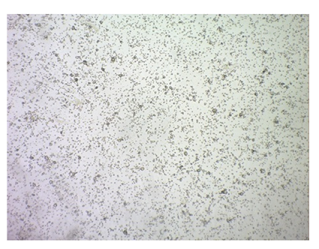

B

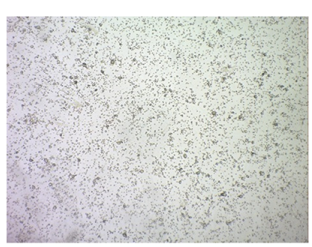

$\mathbf{E}$

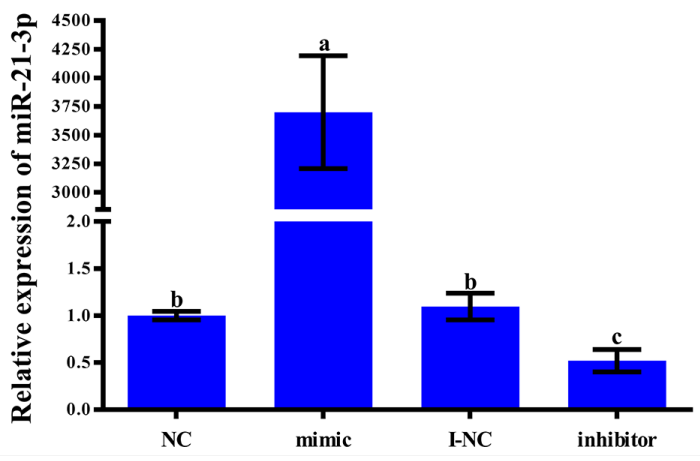

C

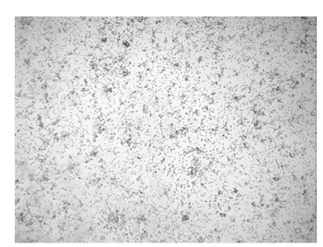

D

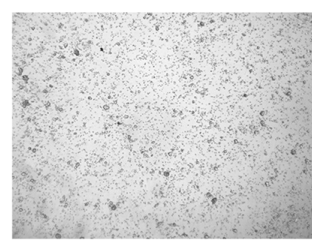

F

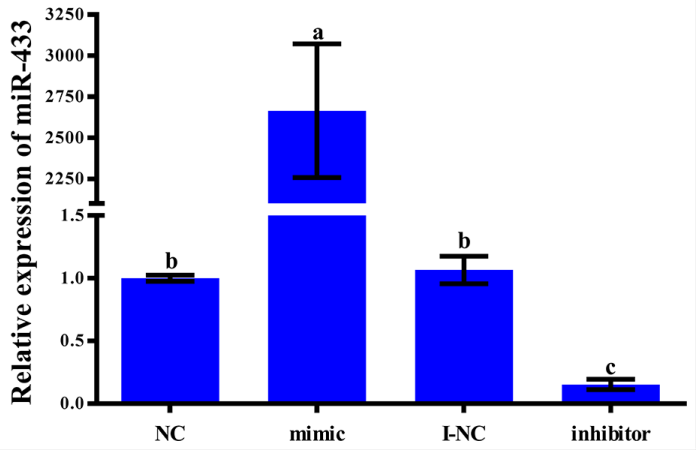

Figure 4: Effect of transfecting rat primary pituitary cells with miR-21-3p and miR-433. After a 24-h transfection period, the rat primary pituitary cells in the blank group (A), the negative control group (B), the miR-21-3p mimic group (C), and the miR-433 mimic group (D) are shown. Magnification, 40×. Rat anterior pituitary cells were transfected with the mimic negative controls (NC), mimics, inhibitor negative controls (I-NC) and inhibitors of miR-21-3p and miR-433. (E-F) The relative expression of miR-21-3p and miR-433 was detected separately using quantitative RT-PCR with U6 as an internal control. All data are presented as the mean \pm standard deviation from at least three independent experiments; statistical significance was determined via one-way ANOVA; and $\mathrm{P}<0.05$ was considered significant. The panels with different letters were considered statistically significant $(\mathrm{P}<0.05)$. 
34]. In 2013, Tushar et al. found that miR-21 targets the SMAD family member 7 (SMAD7) 3'UTR to reduce its expression in hematopoietic cells and plays a role in regulating transforming growth factor- $\beta$ (TGF- $\beta$ ) signaling [35]. Amitava et al. showed that miR-21 functions in the resolution of wound inflammation [36], and the induction of miR-21 is associated with the silencing of phosphatase and tensin homolog on chromosome ten (PTEN) and programmed cell death 4 (PDCD4), which are tumor-suppressor genes targeted by miR-21 [36-39]. An analysis of pituitary cells revealed that miR-21 is underexpressed (2.4-fold) in ACTHsecreting pituitary adenomas compared with normal pituitary tissues [40]. Moreover, miR-21 is associated with not only pituitary adenomas but also hormone secretion from normal pituitary cells. Our results show that miR-21 can regulate the expression levels of FSHb in rat pituitary cells and reveal that miR-21 might participate in the regulation of animal reproduction in addition to the regulation of pituitary adenomas.

miR-433 is located on chromosome 14q32 and exhibits functions in many types of mammalian cells [41]. Recent reports have shown that miR-433 exerts functions in human tumorigenesis and development [42]. Some researchers have found an association between miR-433 and human glioma, gastric carcinoma, myeloproliferative neoplasms and ovarian, liver and other cancers [42-46]. In another study, Xiao-chun Wang et al. observed that miR-433 acts as a tumor suppressor and inhibits oral squamous cell carcinoma (OSCC) cell growth, invasion and migration by targeting histone deacetylase 6 (HDAC6) [47]. Furthermore, miR-433 inhibits retinoblastoma by suppressing the expression levels of notch homolog 1 (Notch1) and

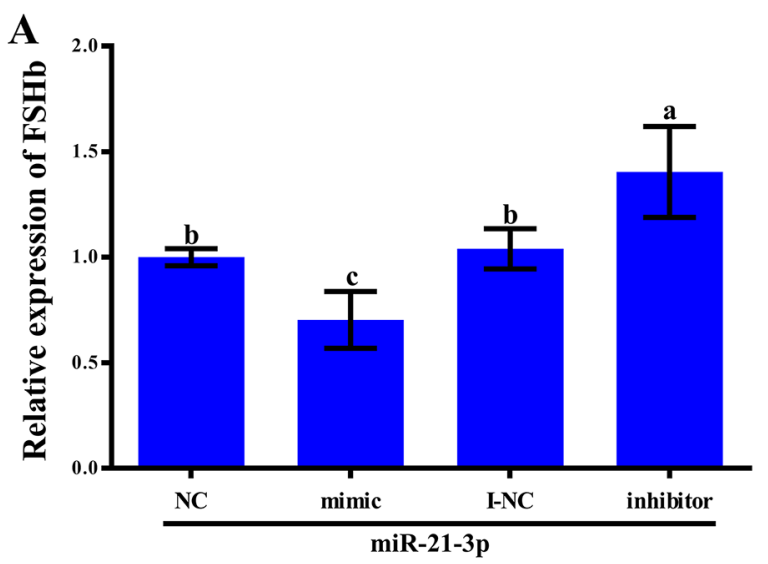

C

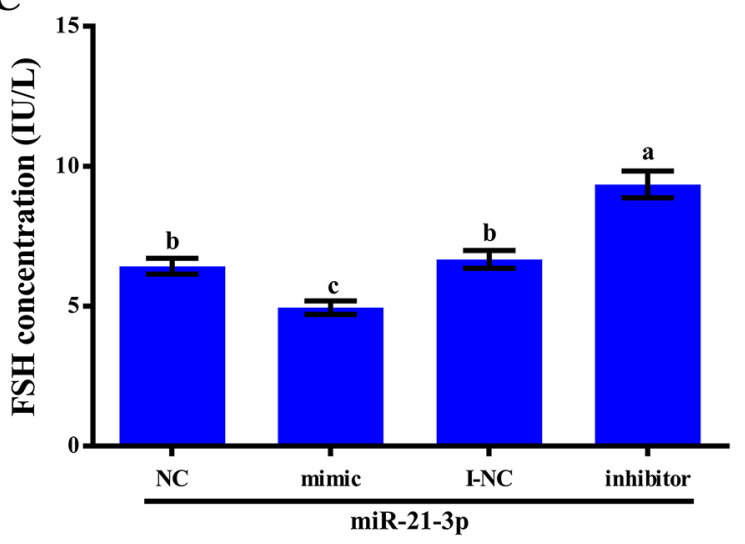

B

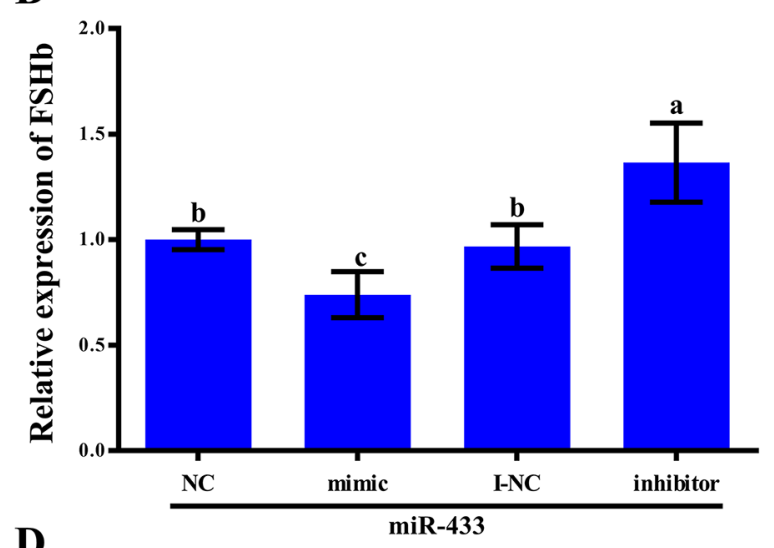

D

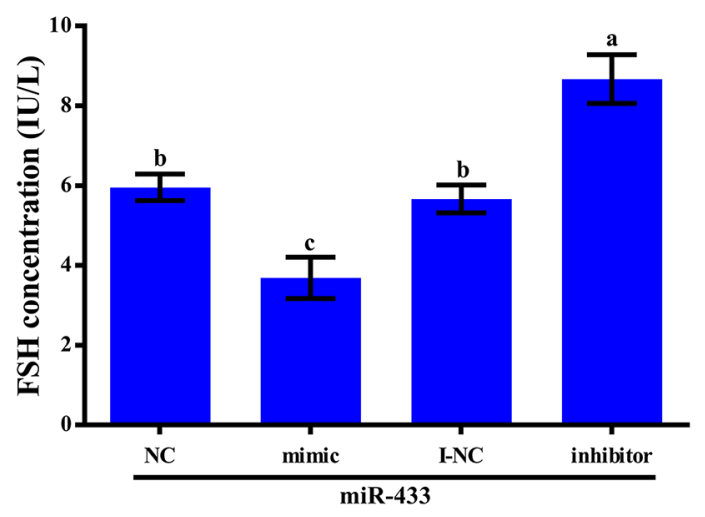

Figure 5: miR-21-3p- and miR-433-mediated regulation of the FSHb expression levels in and FSH secretion by rat primary pituitary cells. (A-B) Rat anterior pituitary cells were transfected with mimic negative controls (NC), mimics, inhibitor negative controls (I-NC) and inhibitors of miR-21-3p and miR-433. The relative expression of FSHb was detected using quantitative RTPCR with GAPDH as an internal control. (C-D) Rat anterior pituitary cells were transfected with mimic negative controls (NC), mimics, inhibitor negative controls (I-NC) and inhibitors of miR-21-3p and miR-433. A total of $50 \mu 1$ of supernatant from the pituitary cells was collected and examined with a Rat FSH Elisa Kit at $24 \mathrm{~h}$ after transfection. All data are presented as the mean \pm standard deviation from at least three independent experiments; statistical significance was determined via one-way ANOVA; and $\mathrm{P}<0.05$ was considered significant. The panels with different letters are statistically significant $(\mathrm{P}<0.05)$. 
paired box protein Pax-6 (PAX6) [48]. Nevertheless, the role of miR-433 in pituitary adenomas has not been investigated. Regarding hormone secretion, in 2012, Riester et al. reported that ACTH stimulation could modulate the adrenal response by influencing miR-433 to act as an endogenous modulator of the glucocorticoid receptor $(\mathrm{Nr} 3 \mathrm{c} 1)$ [49]. Similar to miR-21, the role of miR-433 in pituitary hormone secretion remains largely unknown due to a lack of relevant studies. However, our results show that miR-433 can regulate the FSHb expression levels, which provides data on the regulation of hormone secretion in the pituitary by miRNAs.

FSH is an important endocrine hormone that is essential for mammals; therefore, elucidation of the regulatory mechanisms of FSH is particularly noteworthy. Previous studies have indicated that many factors can regulate the expression levels of the $\mathrm{FSHb}$ gene or secretion of FSH, such as cis-regulatory elements, relevant hormones, SNPs, and upstream regulators $[9,11,50]$. In 2015, Lisheng Dai et al. reported that a novel cis-regulatory element generated from the 5'-upstream regulatory region of the $\mathrm{FSHb}$ gene can influence FSHb expression in bovine cells [51]. In male adult rats, the FSH levels are elevated after pretreatment with a dynorphin (Dyn) antagonist [52]. Other researchers have indicated that a decrease in the serum FSH levels due to the presence of a SNP reduces the induction of $\mathrm{FSHb}$ transcription in humans [53]. Although many factors participate in the regulation of FSH secretion, few studies have investigated the miRNAs that regulate FSH secretion. One such study showed that miR-361-3p negatively regulates FSH secretion [10]. Another study found that GnRH exerts an effect on the proliferation of gonadotropic cells [54] and that increasing the number of gonadotropic cells can increase FSH secretion. Moreover, the up-regulation of miR-133 could stimulate GnRH and further impact FSH release [10]. In our study, we found that the up-regulation of miR-21-3p inhibits FSHb expression and leads to decrease of FSH levels, whereas the down-regulation of miR-21-3p results in stimulating FSH secretion. In addition, miR-433 and miR-21-3p exert the same regulatory effects on FSH secretion. Our results provide further evidence of the participation of miRNAs in the regulation of FSH release. Interestingly, we identified 12 other miRNAs (miR-323-3p, miR-328a-3p, miR-35733p, miR-204-5p, miR-206-5p, miR-31a-5p, miR-7a-5p, miR-880-3p, miR-186-5p, miR-503-5p, miR-383-5p and miR-320-3p) that might also regulate FSHb expression, and then affected FSH secretion, but their specific effects need to be verified through further experiments.

Taken together, our results show that both miR21-3p and miR-433 down-regulate FSHb expression and cause FSH secretion decreased. These findings provide insights into the effects of the regulatory mechanisms of miRNAs on the reproductive functions of the pituitary.

\section{MATERIALS AND METHODS}

\section{Ethics statement}

The experiment was strictly conducted in accordance with the guidelines of the Guide for the Care and Use of Laboratory Animals of Jilin University. The protocol was approved by the Institutional Animal Care and Use Committee of Jilin University (Permit Number: 20160312).

\section{Animals and cell culture}

Nine healthy adult male Wistar rats (4 month of age) and four healthy male Wistar rats (15 days of age) were obtained from the School of Medical Science of Jilin University. The four male 4-month old Wistar rats and four male 15-day old Wistar rats were used to detect the expression of the miRNAs at different developmental stages. And other five male 4-month old Wistar rats were for the cell culture and transfection. To improve the cell culture conditions, we covered six-well plates with $10 \%$ poly-1-lysine (Boster Biology, China) and placed the plates under a humidified atmosphere containing $5 \% \mathrm{CO}_{2}$ at $37^{\circ} \mathrm{C}$ for $12 \mathrm{~h}$. Before using six-well plates, we washed the wells three times with PBS for 5-8 min each at ambient temperature. We euthanized the rats, immediately removed their pituitary glands and placed the glands in ice-cold PBS supplemented with $0.3 \%$ BSA (Sigma, USA) and $1 \%$ penicillin/streptomycin (HyClone, USA) to wash the blood from the tissue. After washing, the neurohypophysis was removed from the pituitary glands, then the glands were transferred to Dulbecco's Modified Eagle's Medium/ Nutrient Mixture F12 (DMEM/F12) (HyClone, USA) containing $2.5 \%$ collagenase type I (Gibco, USA), and the glands were then cut into pieces with ophthalmic scissors. We subsequently placed the treated pituitary glands in a water bath at $37^{\circ} \mathrm{C}$ for $90 \mathrm{~min}$, added PBS to the digested pituitary samples in the wells and placed the mixtures on ice. The cell suspensions were subsequently filtered through a 200 -mesh $(75-\mu \mathrm{m})$ sieve to separate the undigested tissue and cell aggregates and then subjected to centrifugation at $200 \mathrm{~g}$ for $10 \mathrm{~min}$. The obtained cell precipitate was diluted with DMEM/F12 (HyClone, USA) containing $15 \%$ fetal bovine serum (Gibco, USA), $100 \mathrm{IU} /$ $\mathrm{mL}$ penicillin, and $100 \mu \mathrm{g} / \mathrm{mL}$ streptomycin. Finally, $2 \mathrm{ml}$ of the cell suspension was seeded into six-well plates, and the plates were cultured at $37^{\circ} \mathrm{C}$ under a humidified atmosphere containing $5 \% \mathrm{CO}_{2}$.

\section{RNA isolation and quantitative RT-PCR detection}

Total RNA was extracted using the miRcute mRNA Extraction and Separation Kit and the TRIzol reagent (Tiangen, Beijing, China) according to the 
manufacturer's recommended protocol. The total quantity of RNA was assessed with a NanoDrop ND2000 spectrophotometer (NanoDrop Technologies). We then transformed the total RNA into cDNA using the FastQuant RT Kit (with gDNase) according to the manufacturer's instructions (Tiangen, China). Quantitative RT-PCR was subsequently performed with a Mastercycler ep Realplex ${ }^{2}$ system (Eppendorf, Germany) and SuperReal PreMix Plus (SYBR Green) according to the manufacturer's instructions (Tiangen, China). The mRNA and miRNA primers used in these assays are listed in the Supplementary File 1.

\section{Transfection of miRNA mimics and inhibitors}

All miRNA mimics and inhibitors were purchased from Guangzhou RiboBio Biotech Co., Ltd. The transfection of rat pituitary cells was referred to the previous study [55]. Rat anterior pituitary cells were seeded at a density of $3 \times 10^{5}$ cells per well in a 24 -well plate. Transfection was performed with a Lipofectamine 3000 Transfection Kit (Thermo Fisher Scientific, Waltham, USA) according to the manufacturer's recommended protocol. The final concentrations of the miRNA mimics, inhibitors and negative controls were $100 \mathrm{nM}$. After transfection, the cells were incubated for $24 \mathrm{~h}$ for gene expression analysis.

\section{Construction of the pmiR-FSHb-3'UTR-WT and pmiR-FSHb-3'UTR-MUT reporter plasmids}

The full-length 3'UTR of the rat FSHb mRNA (GenBank Accession No. NM_001007597.2) was cloned between the XhoI and NotI sites of the pmiR-RBREPORT $^{\mathrm{TM}}$ plasmid, generating the pmiR-FSHb-3'UTRWT plasmid (Supplementary File 2). We introduced site-specific mutations into the pmiR-FSHb-3'UTR-WT plasmid to interrupt the binding sites of miR-21-3p and miR-433, producing the pmiR-FSHb-3'UTR-MUT and pmiR-FSHb-3'UTR-MUT1 plasmids (Supplementary File 3). Guangzhou Ribobio Biotech Co., Ltd., assisted in the construction of the reporter plasmids. All construct products were confirmed via sequencing (Ribobio Biotech Co., Ltd., Guangzhou, China).

\section{Luciferase reporter assay}

To identify the target miRNAs, we cotransfected $293 \mathrm{~T}$ cells with 45 miRNA mimics, negative controls, pmiR-FSHb-3'UTR-WT and pmiR-RB-REPORT ${ }^{\mathrm{TM}}$. For the analysis of miR-21-3p and miR-433, 293T cells were cotransfected with the mimics, negative controls, pmiR-FSHb-3'UTR-WT, pmiR-FSHb-3'UTR-MUT, pmiR-FSHb-3'UTR-MUT1 and pmiR-RB-REPORT ${ }^{\mathrm{TM}}$. The $293 \mathrm{~T}$ cells were seeded at a density of $1.5 \times 10^{4}$ cells per well with $100 \mu \mathrm{l}$ of DMEM in 96-well plates and transfected using the Lipofectamine 2000 reagent (Invitrogen, USA). After transfection for $48 \mathrm{~h}$, the luciferase activity was measured using a fluorescence intensity meter (Veritas 9100-002), and the experiments were repeated at least three times. Renilla luciferase was used as an internal reference luciferase to minimize experimental variability.

\section{FSH detection}

We collected $50 \mu \mathrm{l}$ of the supernatant from pituitary cells after incubation for $24 \mathrm{~h}$ following transfection. We measured the FSH levels under the different experimental conditions using a Rat FSH ELISA kit according to the manufacturer's instructions (Haling Biotech Co., Ltd., Shanghai, China).

\section{Statistical analysis}

All data are expressed as the means \pm standard deviations from three independent experiments. Significant differences were determined via one-way ANOVA for multiple comparisons using SPSS 19.0 for Windows. $\mathrm{P}<0.05$ was considered statistically significant.

\section{Author contributions}

B.Y. and J.B.Z. were responsible for the main conception and design of the study; D.X.H., X.L.S., and M.Q.X. performed the experiments; D.X.H., C.Z.C., H.J., and Y.G. analyzed the data and contributed reagents; D.X.H., B.Y., and J.B.Z. wrote the manuscript; and all of the authors approved the final version.

\section{CONFLICTS OF INTEREST}

The authors have no conflicts of interest to disclose.

\section{FUNDING}

This study was supported by the National Natural Science Foundation of China (31501954) and the Key Technology R\&D Program (2015BAI07B02 and 20150101102JC).

\section{REFERENCES}

1. Hong GK, Payne SC, Jane JA Jr. Anatomy, Physiology, and Laboratory Evaluation of the Pituitary Gland. Otolaryngol Clin North Am. 2016; 49: 21-32. doi: 10.1016/j. otc.2015.09.002.

2. Yuan B, Han DX, Dai LS, Gao Y, Ding Y, Yu XF, Chen J, Jiang H, Chen CZ, Zhang JB. A comprehensive expression profile of micrornas in rat's pituitary. Int J Clin Exp Med. 2015; 8: 13289-95. 
3. Kumar TR, Wang Y, Lu N, Matzuk MM. Follicle stimulating hormone is required for ovarian follicle maturation but not male fertility. Nat Genet. 1997; 15: 201-4. doi: 10.1038/ ng0297-201.

4. Magalhaes DM, Araujo VR, Lima-Verde IB, Matos MH, Silva RC, Lucci CM, Bao SN, Campello CC, Figueiredo JR. Impact of pituitary FSH purification on in vitro early folliculogenesis in goats. Biocell. 2009; 33: 91-7.

5. Matos MH, Lima-Verde IB, Luque MC, Maia JE Jr, Silva JR, Celestino JJ, Martins FS, Bao SN, Lucci CM, Figueiredo JR. Essential role of follicle stimulating hormone in the maintenance of caprine preantral follicle viability in vitro. Zygote. 2007; 15: 173-82. doi: 10.1017/ S0967199407004169.

6. Coss D, Jacobs SB, Bender CE, Mellon PL. A novel AP-1 site is critical for maximal induction of the folliclestimulating hormone beta gene by gonadotropin-releasing hormone. J Biol Chem. 2004; 279: 152-62. doi: 10.1074/ jbc.M304697200.

7. Telikicherla D, Ambekar A, Palapetta SM, Dwivedi SB, Raju R, Sharma J, Prasad Ts K, Ramachandra Y, Mohan SS, Maharudraiah J, Mukherjee S, Pandey A. A comprehensive curated resource for follicle stimulating hormone signaling. BMC Res Notes. 2011; 4: 408. doi: 10.1186/1756-0500-4-408.

8. George JW, Dille EA, Heckert LL. Current concepts of follicle-stimulating hormone receptor gene regulation. Biol Reprod. 2011; 84: 7-17. doi: 10.1095/ biolreprod.110.085043.

9. Kaiser UB, Jakubowiak A, Steinberger A, Chin WW. Differential effects of gonadotropin-releasing hormone $(\mathrm{GnRH})$ pulse frequency on gonadotropin subunit and $\mathrm{GnRH}$ receptor messenger ribonucleic acid levels in vitro. Endocrinology. 1997; 138: 1224-31. doi: 10.1210/ endo.138.3.4968.

10. Ye RS, Xi QY, Qi Q, Cheng X, Chen T, Li H, Kallon S, Shu G, Wang SB, Jiang QY, Zhang YL. Differentially expressed miRNAs after GnRH treatment and their potential roles in FSH regulation in porcine anterior pituitary cell. PLoS One. 2013; 8: e57156. doi: 10.1371/ journal.pone.0057156.

11. Dai L, Zhao Z, Zhao R, Xiao S, Jiang H, Yue X, Li X, Gao Y, Liu J, Zhang J. Effects of novel single nucleotide polymorphisms of the FSH beta-subunit gene on semen quality and fertility in bulls. Anim Reprod Sci. 2009; 114: 14-22. doi: 10.1016/j.anireprosci.2008.08.021.

12. He L, Hannon GJ. MicroRNAs: small RNAs with a big role in gene regulation. Nat Rev Genet. 2004; 5: 522-31. doi: $10.1038 / \mathrm{nrg} 1379$.

13. Zhang B, Wang Q, Pan X. MicroRNAs and their regulatory roles in animals and plants. J Cell Physiol. 2007; 210: 27989. doi: 10.1002/jcp.20869.
14. Guo H, Ingolia NT, Weissman JS, Bartel DP. Mammalian microRNAs predominantly act to decrease target mRNA levels. Nature. 2010; 466: 835-40. doi: 10.1038/nature09267.

15. Lee RC, Feinbaum RL, Ambros V. The C. elegans heterochronic gene lin-4 encodes small RNAs with antisense complementarity to lin-14. Cell. 1993; 75: 843-54.

16. Reinhart BJ, Slack FJ, Basson M, Pasquinelli AE, Bettinger JC, Rougvie AE, Horvitz HR, Ruvkun G. The 21-nucleotide let-7 RNA regulates developmental timing in Caenorhabditis elegans. Nature. 2000; 403: 901-6. doi: 10.1038/35002607.

17. Zhang Z, Florez S, Gutierrez-Hartmann A, Martin JF, Amendt BA. MicroRNAs regulate pituitary development, and microRNA 26b specifically targets lymphoid enhancer factor 1 (Lef-1), which modulates pituitary transcription factor 1 (Pit-1) expression. J Biol Chem. 2010; 285: 3471828. doi: 10.1074/jbc.M110.126441.

18. Elzein S, Goodyer CG. Regulation of human growth hormone receptor expression by microRNAs. Mol Endocrinol. 2014; 28: 1448-59. doi: 10.1210/me.2014-1183.

19. Bhaskaran M, Mohan M. MicroRNAs: history, biogenesis, and their evolving role in animal development and disease. Vet Pathol. 2014; 51: 759-74. doi: 10.1177/0300985813502820.

20. Wienholds E, Plasterk RH. MicroRNA function in animal development. FEBS Lett. 2005; 579: 5911-22. doi: 10.1016/j.febslet.2005.07.070.

21. Houbaviy HB, Murray MF, Sharp PA. Embryonic stem cellspecific MicroRNAs. Dev Cell. 2003; 5: 351-8.

22. Wienholds E, Kloosterman WP, Miska E, Alvarez-Saavedra E, Berezikov E, de Bruijn E, Horvitz HR, Kauppinen S, Plasterk RH. MicroRNA expression in zebrafish embryonic development. Science. 2005; 309: 310-1. doi: 10.1126/ science. 1114519.

23. Bottoni A, Zatelli MC, Ferracin M, Tagliati F, Piccin D, Vignali C, Calin GA, Negrini M, Croce CM, Degli Uberti EC. Identification of differentially expressed microRNAs by microarray: a possible role for microRNA genes in pituitary adenomas. J Cell Physiol. 2007; 210: 370-7. doi: 10.1002/jcp.20832.

24. Palumbo T, Faucz FR, Azevedo M, Xekouki P, Iliopoulos D, Stratakis CA. Functional screen analysis reveals miR-26b and miR-128 as central regulators of pituitary somatomammotrophic tumor growth through activation of the PTEN-AKT pathway. Oncogene. 2013; 32: 1651-9. doi: 10.1038/onc.2012.190.

25. Bottoni A, Piccin D, Tagliati F, Luchin A, Zatelli MC, degli Uberti EC. miR-15a and miR-16-1 down-regulation in pituitary adenomas. J Cell Physiol. 2005; 204: 280-5. doi: 10.1002/jcp.20282.

26. Wei Z, Zhou C, Liu M, Yao Y, Sun J, Xiao J, Ma W, Zhu $\mathrm{H}$, Wang R. MicroRNA involvement in a metastatic nonfunctioning pituitary carcinoma. Pituitary. 2015; 18: 71021. doi: 10.1007/s11102-015-0648-3. 
27. Schneeberger M, Altirriba J, Garcia A, Esteban Y, Castano C, Garcia-Lavandeira M, Alvarez CV, Gomis R, Claret M. Deletion of miRNA processing enzyme Dicer in POMC-expressing cells leads to pituitary dysfunction, neurodegeneration and development of obesity. Mol Metab. 2012; 2: 74-85. doi: 10.1016/j.molmet.2012.10.001.

28. Zhang N, Lin JK, Chen J, Liu XF, Liu JL, Luo HS, Li YQ, Cui S. MicroRNA 375 mediates the signaling pathway of corticotropin-releasing factor (CRF) regulating proopiomelanocortin (POMC) expression by targeting mitogen-activated protein kinase 8. J Biol Chem. 2013; 288: 10361-73. doi: 10.1074/jbc.M112.425504.

29. Nemoto T, Mano A, Shibasaki T. Increased expression of miR-325-3p by urocortin 2 and its involvement in stressinduced suppression of LH secretion in rat pituitary. Am J Physiol Endocrinol Metab. 2012; 302: E781-7. doi: 10.1152/ajpendo.00616.2011.

30. Sheedy FJ. Turning 21: Induction of miR-21 as a Key Switch in the Inflammatory Response. Front Immunol. 2015; 6: 19. doi: 10.3389/fimmu.2015.00019.

31. Iorio MV, Ferracin M, Liu CG, Veronese A, Spizzo R, Sabbioni S, Magri E, Pedriali M, Fabbri M, Campiglio M, Menard S, Palazzo JP, Rosenberg A, et al. MicroRNA gene expression deregulation in human breast cancer. Cancer Res. 2005; 65: 7065-70. doi: 10.1158/0008-5472. CAN-05-1783.

32. Bandres E, Cubedo E, Agirre X, Malumbres R, Zarate R, Ramirez N, Abajo A, Navarro A, Moreno I, Monzo M, Garcia-Foncillas J. Identification by Real-time PCR of 13 mature microRNAs differentially expressed in colorectal cancer and non-tumoral tissues. Mol Cancer. 2006; 5: 29. doi: 10.1186/1476-4598-5-29.

33. Yanaihara N, Caplen N, Bowman E, Seike M, Kumamoto K, Yi M, Stephens RM, Okamoto A, Yokota J, Tanaka T, Calin GA, Liu CG, Croce CM, et al. Unique microRNA molecular profiles in lung cancer diagnosis and prognosis. Cancer Cell. 2006; 9: 189-98. doi: 10.1016/j.ccr.2006.01.025.

34. Chao TF, Xiong HH, Liu W, Chen Y, Zhang JX. MiR-21 mediates the radiation resistance of glioblastoma cells by regulating PDCD4 and hMSH2. J Huazhong Univ Sci Technolog Med Sci. 2013; 33: 525-9. doi: 10.1007/ s11596-013-1153-4.

35. Bhagat TD, Zhou L, Sokol L, Kessel R, Caceres G, Gundabolu K, Tamari R, Gordon S, Mantzaris I, Jodlowski T, Yu Y, Jing X, Polineni R, et al. miR-21 mediates hematopoietic suppression in MDS by activating TGFbeta signaling. Blood. 2013; 121: 2875-81. doi: 10.1182/ blood-2011-12-397067.

36. Das A, Ganesh K, Khanna S, Sen CK, Roy S. Engulfment of apoptotic cells by macrophages: a role of microRNA-21 in the resolution of wound inflammation. J Immunol. 2014; 192: 1120-9. doi: 10.4049/jimmunol.1300613.

37. Asangani IA, Rasheed SA, Nikolova DA, Leupold JH, Colburn NH, Post S, Allgayer H. MicroRNA-21 (miR21) post-transcriptionally downregulates tumor suppressor
Pdcd4 and stimulates invasion, intravasation and metastasis in colorectal cancer. Oncogene. 2008; 27: 2128-36. doi: 10.1038/sj.onc.1210856.

38. Bai H, Xu R, Cao Z, Wei D, Wang C. Involvement of miR-21 in resistance to daunorubicin by regulating PTEN expression in the leukaemia K562 cell line. FEBS Lett. 2011; 585: 402-8. doi: 10.1016/j.febslet.2010.12.027.

39. Steelman LS, Navolanic PM, Sokolosky ML, Taylor JR, Lehmann BD, Chappell WH, Abrams SL, Wong EW, Stadelman KM, Terrian DM, Leslie NR, Martelli AM, Stivala F, et al. Suppression of PTEN function increases breast cancer chemotherapeutic drug resistance while conferring sensitivity to mTOR inhibitors. Oncogene. 2008; 27: 4086-95. doi: 10.1038/onc.2008.49.

40. Amaral FC, Torres N, Saggioro F, Neder L, Machado HR, Silva WA Jr, Moreira AC, Castro M. MicroRNAs differentially expressed in ACTH-secreting pituitary tumors. J Clin Endocrinol Metab. 2009; 94: 320-3. doi: 10.1210/jc.2008-1451.

41. Song G, Wang L. A conserved gene structure and expression regulation of miR-433 and miR-127 in mammals. PLoS One. 2009; 4: e7829. doi: 10.1371/ journal.pone.0007829.

42. Sun S, Wang $\mathrm{X}, \mathrm{Xu} \mathrm{X}, \mathrm{Di} \mathrm{H}, \mathrm{Du} \mathrm{J}, \mathrm{Xu}$ B, Wang Q, Wang J. MiR-433-3p suppresses cell growth and enhances chemosensitivity by targeting CREB in human glioma. Oncotarget. 2016; 8:5057-5068. doi: 10.18632/ oncotarget.13789.

43. Luo H, Zhang H, Zhang Z, Zhang X, Ning B, Guo J, Nie N, Liu B, Wu X. Down-regulated miR-9 and miR-433 in human gastric carcinoma. J Exp Clin Cancer Res. 2009; 28: 82. doi: 10.1186/1756-9966-28-82.

44. Weiner-Gorzel K, Dempsey E, Milewska M, McGoldrick A, Toh V, Walsh A, Lindsay S, Gubbins L, Cannon A, Sharpe D, O'Sullivan J, Murphy M, Madden SF, et al. Overexpression of the microRNA miR-433 promotes resistance to paclitaxel through the induction of cellular senescence in ovarian cancer cells. Cancer Med. 2015; 4: 745-58. doi: 10.1002/cam4.409.

45. Lin X, Rice KL, Buzzai M, Hexner E, Costa FF, Kilpivaara O, Mullally A, Soares MB, Ebert BL, Levine R, Licht JD. miR-433 is aberrantly expressed in myeloproliferative neoplasms and suppresses hematopoietic cell growth and differentiation. Leukemia. 2013; 27: 344-52. doi: 10.1038/ leu.2012.224.

46. Yang Z, Tsuchiya H, Zhang Y, Hartnett ME, Wang L. MicroRNA-433 inhibits liver cancer cell migration by repressing the protein expression and function of cAMP response element-binding protein. J Biol Chem. 2013; 288: 28893-9. doi: 10.1074/jbc.M113.502682.

47. Wang XC, Ma Y, Meng PS, Han JL, Yu HY, Bi LJ. miR-433 inhibits oral squamous cell carcinoma (OSCC) cell growth and metastasis by targeting HDAC6. Oral Oncol. 2015; 51: 674-82. doi: 10.1016/j. oraloncology.2015.04.010. 
48. Li X, Yang L, Shuai T, Piao T, Wang R. MiR-433 inhibits retinoblastoma malignancy by suppressing Notch1 and PAX6 expression. Biomed Pharmacother. 2016; 82: 247 55. doi: 10.1016/j.biopha.2016.05.003.

49. Riester A, Issler O, Spyroglou A, Rodrig SH, Chen A, Beuschlein F. ACTH-dependent regulation of microRNA as endogenous modulators of glucocorticoid receptor expression in the adrenal gland. Endocrinology. 2012; 153: 212-22. doi: 10.1210/en.2011-1285.

50. Haisenleder DJ, Dalkin AC, Ortolano GA, Marshall JC, Shupnik MA. A pulsatile gonadotropin-releasing hormone stimulus is required to increase transcription of the gonadotropin subunit genes: evidence for differential regulation of transcription by pulse frequency in vivo. Endocrinology. 1991; 128: 509-17. doi: 10.1210/ endo-128-1-509.

51. Dai L, Xu Y, Yu W, Liu S, Gao Y, Zhang L, Yuan B, Chen J, Ma T, Zhang J. Naturally occurring genetic mutations in the 5'-upstream regulatory region of bovine FSHB generate a novel cis-regulatory element that affects its expression. Anim Genet. 2015; 46: 693-6. doi: 10.1111/age.12348.
52. Ruiz-Pino F, Garcia-Galiano D, Manfredi-Lozano M, Leon S, Sanchez-Garrido MA, Roa J, Pinilla L, Navarro VM, Tena-Sempere M. Effects and interactions of tachykinins and dynorphin on FSH and LH secretion in developing and adult rats. Endocrinology. 2015; 156: 576-88. doi: 10.1210/ en.2014-1026.

53. Benson CA, Kurz TL, Thackray VG. A human FSHB promoter SNP associated with low FSH levels in men impairs LHX3 binding and basal FSHB transcription. Endocrinology. 2013; 154: 3016-21. doi: 10.1210/ en.2013-1294.

54. Miles LE, Hanyaloglu AC, Dromey JR, Pfleger KD, Eidne KA. Gonadotropin-releasing hormone receptor-mediated growth suppression of immortalized LbetaT2 gonadotrope and stable HEK293 cell lines. Endocrinology. 2004; 145: 194-204. doi: 10.1210/en.2003-0551.

55. Kusumoto K, Kikuchi M, Fujiwara K, Horiguchi K, Kouki T, Kawanishi K, Yashiro T. Effect of E-cadherin expression on hormone production in rat anterior pituitary lactotrophs in vitro. Acta Histochem Cytochem. 2010; 43: 83-8. doi: 10.1267/ahc. 10001 . 